\title{
Suplementação de taurina em dietas com duas concentrações proteicas para pós-larvas de camarão-branco-do-pacífico
}

\author{
Plínio Schmidt Furtadoํㅜㄹ Maude Regina de Borba², Paula Fraga Maicáa ${ }^{3}$, Wilson Wasielesky Junior² \\ ${ }^{1}$ Curso de Oceanologia do Instituto de Oceanografia da Universidade Federal do Rio Grande - FURG. Caixa Postal 474, CEP: 96201-900, \\ Rio Grande, RS - Brasil. \\ 2 Laboratório de Maricultura/Instituto de Oceanografia - FURG. Caixa Postal 474, CEP: 96201-900, Rio Grande, RS - Brasil. \\ 3 Programa de Pós-Graduação em Aquicultura/Instituto de Oceanografia - FURG.
}

RESUMO - Este estudo foi realizado com o objetivo de avaliar a possibilidade de reduzir a concentração proteica da dieta para pós-larvas de camarão-branco-do-pacífico (Litopenaeus vannamei) por meio da suplementação do aminoácido taurina. Seis dietas práticas, isoenergéticas $(15,48 \mathrm{~kJ} \mathrm{EM} / \mathrm{g})$, foram formuladas para conter duas concentrações de proteína $(35 \%$ e $45 \%$ proteína bruta, PB), com três níveis de suplementação de taurina $(0,5$ e $10 \mathrm{~g} / \mathrm{kg})$, em arranjo fatorial $2 \times 3$, com quatro repetições. Cem pós-larvas (peso inicial de $0,14 \pm 0,01 \mathrm{~g}$ ) foram estocadas em cada um dos 24 tanques de 45 litros conectados a um sistema de recirculação de água marinha. As dietas experimentais foram distribuídas aos camarões ( $10 \%$ da biomassa) três vezes ao dia, durante 30 dias. A concentração proteica da dieta não influenciou o crescimento nem a utilização alimentar das pós-larvas, mas o efeito benéfico da suplementação das dietas com taurina foi evidente em ambos os níveis proteicos testados. As póslarvas alimentadas com as dietas com maior concentração de taurina (10 g/kg) alcançaram maior peso final, ganho em peso e taxa de crescimento específico e melhor conversão alimentar em comparação àquelas alimentadas com as demais dietas. A taxa de sobrevivência média foi superior a $92 \%$ e não foi afetada pelas dietas experimentais. O nível de $35 \%$ de $\mathrm{PB}$ na dieta (22,58 mg PB/kJ EM) é suficiente para promover o crescimento adequado de pós-larvas de L. vannamei, e o desempenho dos camarões pode ser melhorado com a suplementação de $10 \mathrm{~g}$ taurina $/ \mathrm{kg}$ de ração.

Palavras-chave: aminoácido, camarão, dieta prática, nutrição, proteína

\section{Taurine supplementation of diets with two protein concentrations to Pacific white shrimp post-larvae}

\begin{abstract}
The present study aimed to evaluate the possibility of reducing the dietary protein content for post-larvae of Pacific white shrimp (Litopenaeus vannamei) through diet supplementation with taurine amino acid. Six practical isoenergetic $(15.48 \mathrm{~kJ} \mathrm{ME} / \mathrm{g}$ ) diets were formulated to contain two protein concentrations (35\% and $45 \%$ crude protein, CP) and 3 levels of taurine supplementation $(0,5$ and $10 \mathrm{~g} / \mathrm{kg})$ in a $2 \times 3$ factorial scheme, with four replicates. One hundred postlarvae (initial weight $0.14 \pm 0.01 \mathrm{~g}$ ) were stocked in each of twenty-four $45-\mathrm{L}$ tanks, connected with recirculating marine water system. Shrimps were fed the experimental diets (10\% biomass) 3 times a day for 30 days. Dietary protein concentration did not influence growth neither feed utilization of the post-larvae, but a benefic effect of the diet supplementation with taurine on both protein levels tested was evident. Post-larvae fed diets with the highest taurine supplementation $(10 \mathrm{~g} / \mathrm{kg}) \mathrm{achieved}$ significant higher final weight, weight gain, specific growth rate and better feed conversion than those fed the other diets. Average survival rate was greater than $92 \%$ and it was not affected by experimental diets. Crude protein level of $35 \%$ in the diet $(22.58 \mathrm{mg} \mathrm{CP} / \mathrm{kJ} \mathrm{ME})$ is enough to promote adequate growth of L. vannamei post-larvae and shrimp performance can be improved with supplementation of $10 \mathrm{~g}$ taurine $/ \mathrm{kg}$ of ration.
\end{abstract}

Key Words: amino acid, nutrition, practical diet, protein, shrimp

\section{Introdução}

O camarão-branco-do-pacífico, Litopenaeus vannamei, é o principal peneídeo produzido atualmente no Brasil. O sistema de cultivo amplamente utilizado é o semi-intensivo, que permite o aproveitamento da alimentação natural, embora seja necessário o fornecimento de dietas artificiais nutricionalmente balanceadas, que favoreçam o crescimento dos camarões (Tacon, 2002).

Para o desenvolvimento de dietas eficientes, custoefetivas e ambientalmente sustentáveis, é preciso empregar quantidades adequadas de nutrientes, principalmente de 
proteína. A proteína dietética fornece os aminoácidos essenciais, imprescindíveis para o crescimento (Tacon, 1990), entretanto, seu excesso gera impacto ambiental (Cho \& Bureau, 2001) e prejuízos financeiros, pois é o nutriente mais caro de dietas formuladas (Shiau, 1998). Segundo Tacon (1990), mesmo camarões de hábito alimentar onívoro, como o L. vannamei, necessitam de quantidades elevadas de proteína bruta $(\mathrm{PB})$ na dieta durante as fases iniciais, exigência que diminui conforme o seu desenvolvimento: 55 a 35\% PB da fase larval à engorda.

Visando melhorar o desempenho produtivo de peixes e crustáceos, muitos autores têm testado a adição de substâncias na dieta. Entre estas substâncias, a taurina (ácido 2-aminoetanosulfônico) surgiu como um composto promissor, pois é um aminoácido livre, não-essencial, e que está envolvido em importantes funções fisiológicas no organismo animal (Huxtable, 1992; Cañas, 2002). Além disso, possui características de estimulante alimentar (Carr, 1982; Coman et al., 1996), tornando sua inclusão na dieta recomendável sempre que se busca atingir o desempenho máximo em aquicultura (Martinez et al., 2004).

Estudos sobre a suplementação de taurina na dieta de organismos aquáticos são recentes e em sua maioria foram desenvolvidos com peixes. Aumentos significativos no crescimento e na eficiência alimentar foram verificados em várias espécies (Martinez et al., 2004; Lunger et al., 2007; Chatzifotis et al., 2008; Matsunari et al., 2008). Em peneídeos, Shiau \& Chou (1994) obtiveram melhora no desempenho de camarão-tigre, Penaeus monodon, com a suplementação de taurina na dieta, entretanto, não há na literatura relatos sobre a suplementação de taurina em dietas para L. vannamei. Dessa forma, objetivou-se com este trabalho avaliar o efeito da suplementação de taurina em dietas com duas concentrações proteicas para pós-larvas de L. vannamei.

\section{Material e Métodos}

O experimento foi realizado nas instalações da Estação Marinha de Aquicultura Prof. Marcos Alberto Marchiori, do Instituto de Oceanografia da Universidade Federal do Rio Grande, Rio Grande-RS - Brasil, utilizando-se camarões provenientes do Laboratório Aquatec Ltda (Canguaretama, no Rio Grande do Norte, Brasil). Após a chegada nas instalações, os náuplios de L. vannamei foram mantidos no setor de larvicultura de camarões marinhos e cultivados segundo metodologia adaptada de Marchiori (1996) até sua utilização no experimento.

Utilizou-se um delineamento experimental inteiramente casualizado em esquema fatorial $2 \times 3$, composto de duas concentrações de proteína bruta (PB), 35 e $45 \%$ PB, e três níveis de suplementação com taurina (aminoácido cristalinoSigma Aldrich), 0, 5 e $10 \mathrm{~g} / \mathrm{kg}$, com quatro repetições por dieta, todas formuladas para ser isoenergéticas $(15,48 \mathrm{~kJ} / \mathrm{g}$ de energia metabolizável estimada, EM).

Para formulação das dietas experimentais (Tabela 1), os ingredientes foram previamente analisados quanto à sua composição centesimal (matéria seca, proteína bruta, extrato etéreo, fibra bruta e cinzas), segundo metodologias padrão descritas pela AOAC (1999). As fontes proteicas utilizadas (farinha de peixe, farelo de soja e gelatina) foram adicionadas em diferentes quantidades para compor o maior e menor nível proteico, mantendo a mesma proporção em todas as dietas.

Os percentuais de proteína bruta adotados foram baseados em recomendações de Tacon (1990) de no mínimo $45 \%$ em dietas para espécies onívoras de camarão na fase pós-larva (de 25 dias até $1 \mathrm{~g}$ ). Dessa forma, $45 \%$ proteína bruta foi considerado o nível proteico ótimo e $35 \%$ o nível subótimo.

As dietas foram preparadas misturando-se inicialmente os ingredientes secos e adicionando em seguida os óleos e a água $\left(50 \pm 5^{\circ} \mathrm{C}\right)$. A massa homogênea resultante foi passada por uma matriz com orifícios de $3 \mathrm{~mm}$ e levada para secagem em estufa de ventilação forçada a $60^{\circ} \mathrm{C}$. Após secagem, as dietas foram trituradas e peneiradas para obtenção de diferentes granulometrias (850 a $1.800 \mu \mathrm{m})$, embaladas em sacos plásticos, que foram hermeticamente fechados, e armazenadas a $-20^{\circ} \mathrm{C}$ até sua utilização.

Para avaliação da estabilidade das dietas experimentais, $2 \mathrm{~g}$ de ração foram colocados em bandejas de alimentação e depositados nos tanques, em triplicata, anteriormente à estocagem dos camarões. Após 2 horas de imersão na água $\left(26^{\circ} \mathrm{C}\right.$ e $25 \%$ ), a ração remanescente em cada bandeja foi coletada e seca em estufa a $105^{\circ} \mathrm{C}$ até peso constante. Os resultados do cálculo de estabilidade das dietas $(\mathrm{ED}=[\mathrm{Peso}$ seco dieta final/peso seco dieta inicial] $\times 100$ ) variaram de 90 a $91 \%$ e foram utilizados na quantificação do consumo alimentar.

Grupos de 100 pós-larvas de 35 dias de L. vannamei foram estocados (460 camarões $/ \mathrm{m}^{2}$ ) em 24 tanques retangulares de polietileno $(0,66 \times 0,33 \times 0,33 \mathrm{~m})$ com volume útil de $45 \mathrm{~L}$, conectados a um sistema de recirculação com fluxo contínuo de água marinha de aproximadamente $1,2 \mathrm{~L} /$ minuto e aeração individual. Após dez dias de adaptação às condições experimentais, período em que as pós-larvas foram alimentadas na taxa de $10 \%$ da biomassa em cada tanque com uma dieta comercial (Inve-50\% proteína bruta), três vezes ao dia (às $8,13 \mathrm{e}$ $18 \mathrm{~h}$ ), foi realizada a biometria inicial dos camarões. 
Tabela 1 - Composição das dietas experimentais

\begin{tabular}{|c|c|c|c|c|c|c|}
\hline \multirow[t]{3}{*}{ Ingrediente } & \multicolumn{6}{|c|}{ Nível de taurina (g/kg de ração) } \\
\hline & 0,0 & 5,0 & 10,0 & 0,0 & 5,0 & 10,0 \\
\hline & \multicolumn{3}{|c|}{$35 \%$ de $\mathrm{PB}$} & \multicolumn{3}{|c|}{$45 \%$ de $\mathrm{PB}$} \\
\hline Farinha de peixe & 24,50 & 24,50 & 24,50 & 33,06 & 33,06 & 33,06 \\
\hline Farelo de soja & 22,25 & 22,25 & 22,25 & 29,84 & 29,84 & 29,84 \\
\hline Farinha de trigo & 25,69 & 25,69 & 25,69 & 14,00 & 14,00 & 14,00 \\
\hline Gelatina & 5,00 & 5,00 & 5,00 & 7,00 & 7,00 & 7,00 \\
\hline Óleo fígado de bacalhau & 2,40 & 2,40 & 2,40 & 1,65 & 1,65 & 1,65 \\
\hline Óleo de soja & 2,40 & 2,40 & 2,40 & 1,65 & 1,65 & 1,65 \\
\hline Lecitina de soja & 0,50 & 0,50 & 0,50 & 0,50 & 0,50 & 0,50 \\
\hline Colesterol & 0,50 & 0,50 & 0,50 & 0,50 & 0,50 & 0,50 \\
\hline Carboximetilcelulose & 1,50 & 1,50 & 1,50 & 1,50 & 1,50 & 1,50 \\
\hline Premix vitamínico e mineral ${ }^{1}$ & 2,00 & 2,00 & 2,00 & 2,00 & 2,00 & 2,00 \\
\hline Vitamina $\mathrm{C}$ & 0,14 & 0,14 & 0,14 & 0,14 & 0,14 & 0,14 \\
\hline $\mathrm{K}_{2} \mathrm{HPO}_{4}$ & 1,81 & 1,81 & 1,81 & 0,53 & 0,53 & 0,53 \\
\hline Celulose & 11,31 & 10,81 & 10,31 & 7,63 & 7,13 & 6,63 \\
\hline Taurina $^{2}$ & 0,0 & 0,5 & 1,0 & 0,0 & 0,5 & 1,0 \\
\hline \multicolumn{7}{|c|}{ Composição nutricional (calculada) ${ }^{1}$} \\
\hline Matéria seca $(\%)$ & 94,73 & 95,96 & 96,56 & 97,19 & 96,16 & 96,54 \\
\hline Proteína bruta $(\%)^{1}$ & 34,96 & 34,96 & 34,96 & 44,91 & 44,91 & 44,91 \\
\hline Lipídio $(\%)^{1}$ & 9,08 & 9,08 & 9,08 & 8,50 & 8,50 & 8,50 \\
\hline Cinzas $(\%)^{1}$ & 5,49 & 5,49 & 5,49 & 7,29 & 7,29 & 7,29 \\
\hline Fibra bruta $(\%)^{1}$ & 14,01 & 13,51 & 13,01 & 10,98 & 10,48 & 9,98 \\
\hline ENN $(\%)^{3}$ & 36,42 & 36,92 & 37,42 & 28,23 & 28,73 & 29,23 \\
\hline Energia metabolizável $\left(\mathrm{kJ} \mathrm{g}^{-1}\right)^{4}$ & 15,37 & 15,45 & 15,53 & 15,44 & 15,53 & 15,61 \\
\hline
\end{tabular}

Trinta pós-larvas selecionadas ao acaso de cada unidade experimental foram cuidadosamente secas em papel absorvente, pesadas individualmente $(0,14 \pm 0,01 \mathrm{~g}) \mathrm{e}$ devolvidas aos tanques de origem.

As dietas experimentais foram distribuídas em bandejas de alimentação circulares $(\varnothing=0,15 \mathrm{~m})$, na mesma taxa e frequência de alimentação da aclimatação. Pesagens totais, em grupo, dos camarões de cada tanque foram realizadas a cada 10 dias para ajuste da taxa de arraçoamento. Após 2 horas da alimentação, eram observadas as sobras nas bandejas para ajuste da quantidade de ração a ser fornecida na refeição seguinte, com o objetivo de que não houvesse falta nem muita sobra de alimento em todas as dietas. Ao longo dos 30 dias de experimento, foram feitas observações diárias para registrar e remover os indivíduos mortos.

O fotoperíodo foi mantido em 14 horas luz. Diariamente, foram monitorados a temperatura, a concentração de oxigênio dissolvido, a salinidade e o $\mathrm{pH}$ da água do sistema e semanalmente as concentrações de amônia total e nitrito.

Ao final do experimento, os camarões de cada tanque foram pesados individualmente e o desempenho das póslarvas de L. vannamei foi avaliado considerando o peso final, o ganho de peso ( $\mathrm{GP}=$ peso final - peso inicial $)$, a taxa de crescimento específico $(\mathrm{TCE}=100 \times[(\ln$ peso final $-\ln$ peso inicial)/dias de experimento]), o consumo total $(\mathrm{CT}=$ alimento total consumido (MS) por camarão), a conversão alimentar $(\mathrm{CA}=$ alimento total consumido (MS)/ ganho em peso $)$ e a taxa de sobrevivência $\left(100 \times \mathrm{n}^{0}\right.$ final de camarões/ $\mathrm{n}^{0}$ inicial de camarões).

Após confirmação da homogeneidade das variâncias e distribuição normal dos dados, a análise de variância bifatorial foi aplicada considerando os efeitos das concentrações proteicas das dietas e os níveis de suplementação com taurina, bem como a interação entre esses fatores sobre o desempenho das pós-larvas de L. vannamei. Quando identificadas diferenças $(\mathrm{P}<0,05)$ entre as dietas experimentais, as médias foram comparadas pelo teste Tukey. Os valores em porcentagem sofreram transformação arco-seno para serem analisados (Zar, 1996).

\section{Resultados e Discussão}

Os parâmetros de qualidade de água ao longo do período experimental, incluindo a temperatura $\left(25,0 \pm 0,75^{\circ} \mathrm{C}\right)$, a concentração de oxigênio dissolvido $(5,8 \pm 0,36 \mathrm{mg} / \mathrm{L})$, a salinidade $(24,00 \pm 1,00 \%)$, o $\mathrm{pH}(7,84 \pm 0,08)$ e as concentrações de amônia total $(0,11 \pm 0,01 \mathrm{mg} / \mathrm{L})$ e nitrito 
$(0,05 \pm 0,02 \mathrm{mg} / \mathrm{L})$, não variaram significativamente entre as dietas $(\mathrm{P}>0,05)$ e estiveram dentro dos níveis aceitáveis para o cultivo de peneídeos (Boyd, 1989).

A concentração proteica da dieta não influenciou os parâmetros avaliados $(\mathrm{P}>0,05)$ e também não houve interação $(\mathrm{P}>0,05)$ entre a concentração proteica e os níveis de taurina suplementada à dieta. Entretanto, foi verificado efeito $(\mathrm{P}<0,05)$ da suplementação de taurina no crescimento e na utilização alimentar das pós-larvas de L. vannamei (Tabela 2). O nível mais elevado testado $(10 \mathrm{~g} / \mathrm{kg})$ refletiu em maior peso final, ganho em peso e melhor conversão alimentar em comparação à dieta não suplementadas com taurina $(0 \mathrm{mg} / \mathrm{kg})$ e àquela suplementadas com $5 \mathrm{mg} / \mathrm{kg}$, as quais não diferiram $(\mathrm{P}>0,05)$ entre si. O consumo total médio de ração por camarão e a taxa de sobrevivência, que em geral ficou acima de $92 \%$, não foram influenciados $(\mathrm{P}>0,05)$ pelas dietas experimentais.

Tendo em vista a expansão da aquicultura e o fato de a alimentação ser um dos maiores gastos da atividade, a busca por dietas que promovam crescimento máximo com melhor relação custo-benefício é muito comum. A proteína é o nutriente mais caro de dietas formuladas, desta forma, é importante a definição da concentração mínima que resulte no melhor desempenho animal (Sá \& Fracalossi, 2002; Furuya et al., 2005; Bomfim et al., 2008). O uso de recursos que possibilitem reduzir a concentração proteica da dieta sem prejudicar a produtividade também é de grande interesse e justifica este estudo para avaliação da suplementação de taurina em dietas com concentração proteica ótima e subótima para pós-larvas de L. vannamei (Tacon, 1990).

As informações encontradas na literatura referentes à concentração ótima de proteína na dieta para L. vannamei oscilam de 25 a $48 \%$ de proteína bruta (Shiau, 1998; Kureshy \& Davis, 2002; Martinez-Cordova, 2002). Essa amplitude é em grande parte consequência de diferenças no tamanho dos camarões, na digestibilidade e na palatabilidade dos ingredientes utilizados nas dietas, no balanço de aminoácidos, na relação energia/proteína, nas taxas de alimentação adotadas, assim como fatores ambientais (Cuzon \& Guillaume, 1997; Martinez-Cordova, 2002).

Neste trabalho não houve efeito significativo da concentração proteica da dieta sobre os parâmetros avaliados: o nível de 35 e $45 \%$ de proteína bruta $(22,6$ e $28,9 \mathrm{mg}$ proteína $/ \mathrm{kJ}$, respectivamente) promoveram crescimento e utilização alimentar similares nas pós-larvas de L. vannamei. Esses resultados contrariam as recomendações de Tacon (1990) e Wyk (1999) de dietas com $45 \%$ de proteína bruta para pós-larvas de L. vannamei na faixa de peso utilizadas neste trabalho. A menor exigência de proteína verificada pode estar relacionada, entre outros fatores, à alta qualidade dos principais ingredientes proteicos empregados nas dietas experimentais (farinha de peixe Chilena e farelo de soja 69 e $44 \%$ de proteína bruta, respectivamente), assim como a concentração energética na faixa de 13 a $17 \mathrm{~kJ} / \mathrm{g}$, recomendada para dietas de crustáceos (Cuzon \& Guillaume, 1997), favorecendo desta forma a digestibilidade das dietas.

No cultivo em viveiros, o alimento natural disponível pode contribuir para a satisfação das exigências nutricionais dos camarões (Nunes et al., 1997). Assim, é possível que, em condições práticas de cultivo em fazendas, a concentração de proteína bruta na dieta para pós-larvas de $L$. vannamei na faixa de peso utilizada neste estudo seja ainda menor que $35 \%$ e não prejudique o crescimento.

Como animais aquáticos são bem adaptados a utilizar proteína como fonte de energia, quando o consumo diário desse nutriente excede a exigência da espécie, a proteína é facilmente metabolizada para gerar energia e, consequentemente, é excretado nitrogênio. Desta forma,

Tabela 2 - Desempenho de pós-larvas de camarão-branco-do-pacífico alimentadas com dietas com duas concentrações proteicas suplementadas ou não com taurina, ao final de 30 dias

\begin{tabular}{|c|c|c|c|c|c|c|}
\hline \multirow{3}{*}{$\begin{array}{l}\text { Característica de } \\
\text { desempenho }\end{array}$} & \multicolumn{6}{|c|}{ Nível de taurina ( $\mathrm{g} / \mathrm{kg}$ de ração) } \\
\hline & 0,0 & 5,0 & 10,0 & 0,0 & 5,0 & 10,0 \\
\hline & \multicolumn{3}{|c|}{$35 \%$ de $\mathrm{PB}$} & \multicolumn{3}{|c|}{$45 \%$ de $\mathrm{PB}$} \\
\hline Peso final (mg) & $767,77 \pm 34,47 b$ & $790,80 \pm 23,6 b$ & $891,71 \pm 30,82 \mathrm{a}$ & $787,45 \pm 20,19 b$ & $788,78 \pm 36,44 b$ & $919,27 \pm 35,21 \mathrm{a}$ \\
\hline Ganho de peso (mg) & $631,19 \pm 30,59 b$ & $657,67 \pm 18,08 b$ & $745,81 \pm 3,32 \mathrm{a}$ & $651,82 \pm 21,01 b$ & $656,96 \pm 37,62 b$ & $791,28 \pm 31,09 a$ \\
\hline Taxa de crescimento & & & & & & \\
\hline específico $(\% /$ dia $)$ & $5,67 \pm 0,15 b$ & $5,78 \pm 0,10 \mathrm{~b}$ & $6,17 \pm 0,12 \mathrm{a}$ & $5,76 \pm 0,08 b$ & $5,77 \pm 0,16 b$ & $6,26 \pm 0,13 \mathrm{a}$ \\
\hline Consumo total (mg/pós-larva) & $869,84 \pm 31,05$ & $864,83 \pm 26,68$ & $879,24 \pm 24,24$ & $888,14 \pm 31,02$ & $858,59 \pm 36,85$ & $926,60 \pm 89,46$ \\
\hline Conversão alimentar & $1,38 \pm 0,10 \mathrm{~b}$ & $1,32 \pm 0,06 \mathrm{~b}$ & $1,18 \pm 0,05 \mathrm{a}$ & $1,36 \pm 0,08 \mathrm{~b}$ & $1,31 \pm 0,11 b$ & $1,17 \pm 0,09 \mathrm{a}$ \\
\hline Sobrevivência (\%) & $94,50 \pm 3,42$ & $96,25 \pm 2,99$ & $95,25 \pm 2,63$ & $94,25 \pm 3,51$ & $96,50 \pm 4,27$ & $92,75 \pm 4,35$ \\
\hline
\end{tabular}

Peso inicial pós-larvas: $135,17 \pm 11,25 \mathrm{mg}$. Médias $( \pm \mathrm{DP})$ na mesma coluna com letras diferentes são estatisticamente diferentes $(\mathrm{P}<0,05)$. 
dietas com concentrações excessivas de proteína, além de mais caras, podem afetar a qualidade da água dos viveiros, causando sérios problemas de eutrofização pelo aumento da excreção de compostos nitrogenados (Burford \& Willians, 2001; González-Félix et al., 2007; Quadros et al., 2009). Nesse sentido, Martinez-Cordova et al. (2002) criticaram a tendência dos produtores de camarão em utilizar dietas com altas concentrações proteicas para aumento do crescimento, e salientaram a importância do uso de quantidades adequadas de proteína para atender às exigências dos camarões com o menor custo possível.

De acordo com Tacon (2002), a falta de publicações sobre as exigências nutricionais dos camarões em condições práticas de cultivo em viveiros tem resultado em dietas comerciais, em sua maioria, com excesso de nutrientes, pois a disponibilidade do alimento natural é ignorada. Os bons resultados obtidos com as dietas com $35 \%$ de proteína bruta neste estudo, conduzido em condições de laboratório, sugerem que no mercado brasileiro também pode estar ocorrendo essa discrepância, uma vez que dietas comerciais com mais de $40 \%$ proteína bruta são recomendadas pelos fabricantes para pós-larvas de L. vannamei com menos de $1 \mathrm{~g}$.

Em ambas as concentrações proteicas da dieta, aumentos significativos de crescimento e melhora na conversão alimentar foram verificados para pós-larvas de L. vannamei que receberam suplementação de taurina na proporção de $10 \mathrm{~g} / \mathrm{kg}$. Resultados semelhantes foram obtidos com várias espécies de peixes, com relatos de que a suplementação de taurina em dietas práticas à base de farinha de peixe aumentou o desempenho produtivo de linguado japonês, Paralichtys olivaceus (Kim et al., 2005), robalo-europeu, Dicentrarchus labrax (Martinez et al., 2004), pargo-japonês, Pagrus major (Matsunari et al., 2008), e dentex-comum Dentex dentex (Chatzifotis et al., 2008). Resultados semelhantes aos deste estudo foram observados em juvenis do camarão-tigre (Penaeus monodon), que também se beneficiaram com a suplementação de $8 \mathrm{~g} / \mathrm{kg}$ de taurina em dietas semipurificadas à base de caseína e pequena quantidade de farinha de camarão, melhorando significativamente os índices de crescimento e conversão alimentar (Shiau \& Chou, 1994).

Os mecanismos pelos quais os efeitos benéficos da taurina no metabolismo animal são alcançados ainda não estão claros, tendo em vista as numerosas e importantes funções fisiológicas nas quais esse composto está envolvido (Huxtable, 1992; Cañas, 2002; Takagi et al., 2006). Por suas características químicas (contém nitrogênio, baixo peso molecular, propriedade acidobásica, estabilidade no tratamento com calor e solubilidade em água), esse aminoácido também pode atuar como estimulador alimentar em peixes e crustáceos (Carr, 1982; Coman et al., 1996).

Martinez et al. (2004) verificaram que juvenis de Dicentrarchus labrax consumiram mais ativamente dietas à base de farinha de peixe e farelo de soja suplementadas com 0,2 e $0,3 \%$ de taurina e apresentaram também crescimento significativamente superior. Entretanto, neste estudo a quantidade total de ração consumida pelas pós-larvas de L. vannamei não diferiu significativamente entre as dietas.

A taurina é abundante em vários tecidos animais, onde é encontrada na forma livre ou formando peptídeos simples, e não pode ser utilizada para síntese proteica nem metabolizada para gerar energia (Huxtable, 1992). Dessa forma, o efeito promotor de crescimento em muitos estudos está provavelmente relacionado às ações secundárias ou auxiliares da taurina em outros fenômenos biológicos (Martinez et al., 2004; Chatzifotis et al., 2008). De acordo com Huxtable (1992), entre as numerosas funções fisiológicas em que está envolvida, a taurina é um composto muito importante no metabolismo de lipídios, pois atua como o único aminoácido conjugador de sais biliares em peixes teleósteos, formando os ácidos taurocólico e taurochenodeoxicólico (Goto et al., 1996; Kim et al., 2007), que agem na solubilização ou emulsificação de gorduras, tornando-as mais acessíveis para a digestão (Huxtable, 1992; Chatzifotis et al., 2008).

Os crustáceos, diferentemente dos peixes, são incapazes de sintetizar esteróis (Kanazawa, 2001), mas, por sua grande importância no desenvolvimento e na reprodução animal (Perevozchikov, 2008), devem ser supridos na dieta, preferencialmente na forma de colesterol (Tacon, 1990). Shiau \& Chou (1994) notaram aumento dos níveis de colesterol na hemolinfa de juvenis de $P$. monodon quando elevaram a suplementação de taurina na dieta, sugerindo que também nesses crustáceos os conjugados de taurina agem na solubilização do colesterol e na absorção dos esteróis ingeridos. Dessa forma, considerando os aspectos mencionados, é possível que o melhor desempenho das pós-larvas de L. vannamei neste estudo esteja relacionado à maior eficiência de digestão e absorção do colesterol e dos demais lipídios da dieta como um todo, proporcionada pela suplementação de $10 \mathrm{~g}$ de taurina $/ \mathrm{kg}$.

\section{Conclusões}

O nível de 35\% proteína bruta na dieta (22,58 mg proteína/ $\mathrm{kJ}$ EM) é suficiente para promover o crescimento adequado de pós-larvas de camarão-branco-do-pacífico, L. vannamei. O desempenho dessa espécie pode ser melhorado com a suplementação de taurina no nível de $10 \mathrm{~g} / \mathrm{kg}$ de ração. 


\section{Agradecimentos}

À Nutron Alimentos, pela doação da farinha de peixe, e aos prof. Carlos Prentice-Hernández e Luiz Antônio de Almeida Pinto, pela disponibilização dos equipamentos para a confecção das dietas.

\section{Referências}

ASSOCIATION OF OFFICIAL ANALYTICAL CHEMISTS - AOAC. Official methods of analysis. 16.ed. Washington, D.C.: 1999. $1141 \mathrm{p}$.

BOMFIM, M.A.D.; LANNA, E.A.T.; DONZELE, J.L. et al. Redução de proteína bruta com suplementação de aminoácidos, com base no conceito de proteína ideal, em rações para alevinos de tilápiado-nilo. Revista Brasileira de Zootecnia, v.37, n.10, p.1713-1720, 2008.

BOYD, C.E. Water quality management and aeration in shrimp farming. Alabama: Alabama Agricultural Experiment Station, Auburn University, 1989. 83p. (Fisheries and Allied Aquacultures Departmental Series, 2).

BURFORD, M.A.; WILLIAMS, C.K. The fate of nitrogenous waste from shrimp feeding. Aquaculture, v.198, p.79-93, 2001.

CAÑAS, D.P. Rol biológico y nutricional de la taurina y sus derivados. Revista Chilena de Nutrición, v.29, n.3, p.286-292, 2002.

CARR, W.E.S. Chemical stimulation of feeding behaviour. In: HARA, T.J. (Ed.) Chemoreception in fishes. Amsterdam: Elsevier, 1982. p.259-273.

CHATZIFOTIS, S.; POLEMITOU, I.; DIVANACH, P. et al. Effect of dietary taurine supplementation on growth performance and bile salt activated lipase activity of common dentex, Dentex dentex, fed a fish meal/soy protein concentrate-based diet. Aquaculture, v.275, p.201-208, 2008.

CHO, C.Y.; BUREAU, D.P. A review of diet formulation strategies and feeding systems to reduce excretory and feed wastes in aquaculture. Aquaculture Research, v.32, p.349-360, 2001.

COMAN, G.J.; SARAC, H.Z.; FIELDER, D. et al. Evaluation of crystaline amino acids, betaine and AMP as food attractants of the giant tiger prawn (Penaeus monodon). Comparative Biochemistry and Physiology, v.113A, p.247-253, 1996.

CUZON, G.; GUILLAUME, J. Energy and protein:energy ratio. In: D'ABRAMO, L.R., CONKLIN, D.E.; AKIYAMA, D.M. (Eds.) Crustacean nutrition, advances in world aquaculture. Baton Rouge: World Aquaculture Society, 1997. v.6, p.51-70.

FURUYA, W.M.; BOTARO, D.; MACEDO, R.M.G. et al. Aplicação do conceito de proteína ideal para redução dos níveis de proteína em dietas para tilápia do Nilo (Oreochromis niloticus). Revista Brasileira de Zootecnia, v.34, n.5, p.1433-1441, 2005.

GONZÁLEZ-FÉLIX, M.L.; GÓMEZ-JIMÉNEZ, S.; PEREZVELASQUEZ, M. et al. Nitrogen budget for a low salinity, zero-water exchange culture system: I. Effect of dietary protein level on the performance of Litopenaeus vannamei (Boone). Aquaculture Research, v.38, p.798-808, 2007.

GOTO, T.; UI, T.; UNE, M. et al. Bile salt composition and distribution of the D-cysteinolic acid conjugated bile salts in ûsh. Fisheries Science, v.62, p.606-609, 1996.

HUXTABLE, R.J. Physiological actions of taurine. Physiological Reviews, v.72, p.101-163, 1992.

KANAZAWA, A. Sterols in marine invertebrates. Fisheries Science, v.67, p.997-1007, 2001.

KIM, S.K.; MATSUNARI, H.; TAKEUCHI, T. et al. Effect of different dietary taurine levels on the conjugated bile acid composition and growth performance of juvenile and fingerling Japanese flounder Paralichthys olivaceus. Aquaculture, v.273, p.595-601, 2007.

KIM, S.K.; TAKEUCHI, T.; AKIMOTO, A. et al. Effect of taurine supplemented practical diet on growth performance and taurine contents in whole body and tissues of juvenile Japanese ûounder Paralichthys olivaceus. Fisheries Science, v.71, p.627-632, 2005.

KURESHY, N.; DAVIS, D.A. Protein requirement for maintenance and maximum weight gain for the Pacific white shrimp, Litopenaeus vannamei. Aquaculture, v.204, p.125-143, 2002.

LEE, D.J.; PUTNAM, G.B. The response of rainbow trout to varying protein/energy ratios in a test diet. Journal of Nutrition, v.103, p.916-922, 1973.

LUNGER, A.N.; MCLEAN, E.; GAYLORD, T.G. et al. Taurine supplementation to alternative dietary proteins used in fish meal replacement enhances growth of juvenile cobia (Rachycentron canadum). Aquaculture, v.271, p.401-410, 2007.

MARCHIORI, M.A. Guia ilustrado de maturação e larvicultura do camarão-rosa Penaeus paulensis Pérez- Farfante, 1967. Rio Grande: FURG, 1996. 79p.

MARTINEZ, J.B.; CHATZIFOTIS, S.; DIVANACH, P. Effect of dietary taurine supplementation on growth performance and feed selection of sea bass Dicentrarchus labrax fry fed with demand-feeders. Fisheries Science, v.70, p.74-79, 2004.

MARTINEZ-CORDOVA, L.R.; CAMPANA-TORRES, A.; PROCHAS-CORNEJO, M.A. The effects of variation in feed protein level on the culture of white shrimp, Litopenaeus vannamei (Boone) in low-water exchange experimental ponds. Aquaculture research, v.33, p.995-998, 2002.

MATSUNARI, H.; FURUITA, H.; YAMAMOTO, T. et al. Effect of dietary taurine and cystine on growth performance of juvenile red sea bream Pagrus major. Aquaculture, v.274, p.142-147, 2008.

NUNES, A.J.P.; GESTEIRA, T.C.V.; GODDARD, S. Food ingestion and assimilation by the Southern brown shrimp Penaeus subtilis under semi-intensive culture in NE Brazil. Aquaculture, v.149, p.121-136, 1997.

PEREVOZCHIKOV, A.P. Sterols and their transport in animal development. Russian Journal of Developmental Biology, v.39, n.3, p.131-150, 2008.

QUADROS, M.; LANNA, E.A.T.; DONZELE, J.L. et al. Crude protein reduction and digestible methionine+cystine and threonine to digestible lysine ratios in diets for Nile tilapia fingerlings. Revista Brasileira de Zootecnia, v.38, n.8, p.1400-1406, 2009.

SÁ, M.V.C.; FRACALOSSI, D.M. Exigência protéica e relação energia/proteína para alevinos de piracanjuba (Brycon orbignyanus). Revista Brasileira de Zootecnia, v.31, n.1, p.1-10, 2002.

SHIAU, S.Y. Nutrient requirements of penaeid shrimps. Aquaculture, v.164, p.77-93, 1998.

SHIAU, S.Y.; CHOU, B.S. Grass shrimp, Penaeus monodon, growth as influenced by dietary taurine supplementation. Comparative Biochemistry and Physiology Part A: Physiology, v.108, p.137-142, 1994.

TACON, A.G.J. The nutrition and feeding of farmed fish and shrimp - A training manual. The essential nutrients. Brasilia: FAO, 1990. 117p.

TACON, A.G.J. Thematic review of feeds and feed management practices in shrimp aquaculture. Report prepared under the World Bank, NACA, WWF and FAO Consortium Program on Shrimp Farming and the Environment. Work in Progress for Public Discussion. Kaneohe, HI, USA: Consortium, 2002. 69p.

TAKAGI, S.; MURATA, H.; GOTO, T. et al. Hemolytic suppression roles of taurine in yellowtail Seriola quinqueradiata fed nonûshmeal diet based on soybean protein. Fisheries Science, v.72, p.546-555, 2006.

WYK, P.V. Nutrition and feeding of Litopenaeus vannamei in intensive culture systems. In: WYK, P.V.; DAVIS-HODGKINS, M.; LAMORE, R. et al. (Eds.) Farming marine shrimp in recirculating freshwater systems. Talahassee: Florida Department of Agriculture and Consumer Services, 1999. p.125-140.

ZAR, J.H. Biostatistical analysis. 3.ed. New Jersey: Prentice Hall, 1996. 662p. 